\title{
Characterisation of passive films formed on mild steels in bicarbonate solution by EIS
}

\author{
Valéria A. Alves, Christopher M.A. Brett* \\ Departamento de Quimica, Universidade de Coimbra, 3004-535 Coimbra, Portugal \\ Received 22 June 2001; received in revised form 13 October 2001
}

\begin{abstract}
Passive films formed anodically on carbon steel, chromium steel and high speed steel (HSS) in $0.5 \mathrm{M} \mathrm{NaHCO}_{3}$ and in $0.5 \mathrm{M}$ $\mathrm{NaHCO}_{3}+0.01 \mathrm{M} \mathrm{KCl}$ have been characterised by electrochemical impedance spectroscopy (EIS). Carbon steel presents a wide passive anodic region ( $0.0-0.9 \mathrm{~V}$ vs. saturated calomel electrode (SCE)), while those of chromium steel and HSS, either as-received or heat-treated, are narrower because of transpassive anodic dissolution of $\mathrm{Cr}$ above $\sim 0.4 \mathrm{~V}$. This is clearly seen through changes in the impedance spectra. An equivalent circuit is proposed to fit the experimental data, leading to determination of oxide film capacitance and film resistance. The semiconductor properties of the passive films were investigated by Mott-Schottky plots. All steel samples behave like n-type semiconductors, showing that the passive film properties are dominated by iron. However, same differences are found concerning the concentration of donors, i.e. oxygen vacancies, and thickness of the space charge region, which are correlated with the different pitting corrosion resistances of the passivated steels. (C) 2002 Published by Elsevier Science Ltd.
\end{abstract}

Keywords: Steel; Bicarbonate; Passivation; Electrochemical impedance spectroscopy; Semiconductor properties

\section{Introduction}

Electrochemical impedance spectroscopy (EIS) has been widely used to study and characterise passive films anodically formed on pure metals or alloys [1,2], whose electrical properties are expected to be of crucial importance in the understanding of their protective character against corrosion. Since dissolution, film formation and breakdown involve the movement of electrons and ions, electronic properties represent one of the most significant features of a passive film with respect to its corrosion resistance [3] and which may play an important role in the film breakdown mechanism. The close dependence between breakdown of a passive film and its defective nature has been directly connected with its ionic and electronic conductivity characteristics [4].

Studies on the electrochemical behaviour of carbon steel, chromium steel and high speed steel (HSS) in bicarbonate solutions $[5,6]$ have shown that these steels

* Corresponding author. Tel./fax: +351-239-835295.

E-mail address: brett@ci.uc.pt (C.M.A. Brett). present some different passivation properties. For instance, polarisation curves showed that the steel composition exerts some influence on the onset of passive film formation, chromium and HSSs presenting a higher ability to passivate than carbon steel. The passive current density values, obtained either by potentiodynamic measurements or by chronoamperometry, were higher for HSS than for carbon and chromium steels. The stability of the passive films was investigated after adding $10 \mathrm{mM}$ chloride to the bicarbonate solution. The passive film formed on carbon steel suffered metastable pitting, while those formed on the other, higher-alloyed, steels were stable. This suggests that there are differences in the electronic properties of the passive films.

Based on this, the purpose of this work was to investigate the influence of the steel composition on the electrical properties, and thence corrosion, of anodic passive films, particularly by electrochemical impedance. This especially concerned the presence and content of alloying elements such as $\mathrm{Cr}$, Mo and W. The steel passivating medium was a bicarbonate solution of concentration $0.5 \mathrm{M}$, in which $\mathrm{FeCO}_{3}$ may form a protective film according to the reactions [7]: 
$\mathrm{Fe}+2 \mathrm{H}_{2} \mathrm{O} \rightarrow \mathrm{Fe}(\mathrm{OH})_{2}+2 \mathrm{H}^{+}+2 \mathrm{e}^{-}$

$\mathrm{Fe}+\mathrm{HCO}_{3}^{-} \rightarrow \mathrm{FeCO}_{3}+\mathrm{H}^{+}+2 \mathrm{e}^{-}$

The second reaction, Eq. (2), is dependent on $\mathrm{pH}$ and $\mathrm{HCO}_{3}^{-}$and is favoured by high $\mathrm{HCO}_{3}^{-}$concentration. According to Cheng et al. [8], $0.5 \mathrm{M} \mathrm{HCO}_{3}^{-}$is sufficiently concentrated to make the saturation and stabilisation of $\mathrm{FeCO}_{3}$ easier. Passivation of the steel occurs when the potential becomes sufficiently positive, ascribed to the formation of a $\gamma-\mathrm{Fe}_{2} \mathrm{O}_{3} / \mathrm{Fe}_{3} \mathrm{O}_{4}$ film [9].

\section{Experimental}

Three different types of steels were studied, whose chemical compositions are (in wt.\%): AISI 1015 carbon steel (C, 0.17; Mn, <1.0; $\mathrm{Si},<0.4)$, Calmax chromium steel (Mo, 0.5; Cr, 4.5; V, 0.2; C, 0.6; Mn, 0.8; Si, <0.4) and AISI M2 HSS (W, 6.4; Mo, 5.0; Cr, 4.2; V, 1.9; C, $0.9 ; \mathrm{Mn},<0.4 ; \mathrm{Si},<0.4)$, the balance being Fe. Carbon steel was used as received. Chromium steel and HSS were used as received and also after heat treatment, which consisted of the following steps:

a) austenitising at $950{ }^{\circ} \mathrm{C}$ (chromium steel) or at $1150{ }^{\circ} \mathrm{C}$ (HSS) for $10 \mathrm{~min}$ in an argon atmosphere;

b) quenching in oil down to room temperature;

c) single tempering of $2 \mathrm{~h}$ at $450{ }^{\circ} \mathrm{C}$ (chromium steel) and triple tempering of $2 \mathrm{~h}$ each at $550{ }^{\circ} \mathrm{C}$ (HSS).

Electrodes were prepared by attaching a copper wire to the rear face with silver epoxy and covering with epoxy resin, including the edges of the samples. The exposed faces were polished with silicon carbide papers of 600 and 1000 grit sizes and were then rinsed with water and ethanol.

Non-deaerated solutions of $0.5 \mathrm{M} \mathrm{NaHCO}_{3}(\mathrm{pH}$ 8.6) without and with $0.01 \mathrm{M}$ potassium chloride $(\mathrm{pH} 8.5)$ were prepared using analytical grade reagent and Millipore Milli-Q water.

A three-electrode one-compartment cell, containing a Pt foil auxiliary electrode and a saturated calomel electrode (SCE) as reference was employed. Polarisation curves were registered with a EG\&G PAR 273A Potentiostat controlled by M352 Software. Impedance experiments were carried out using a Solartron 1250 Frequency Response Analyser with a model 1286 Electrochemical Interface, using a $5 \mathrm{mV}$ rms perturbation from $10 \mathrm{kHz}$ down to $25 \mathrm{mHz}$. Experiments were controlled with ZPLOT software and fitting was performed with ZSIM CNLS software. Spectra were recorded over the entire passive anodic region of each steel sample, in $100 \mathrm{mV}$ steps. Before each experiment, the chosen potential was applied during $10 \mathrm{~min}$ in order to obtain a constant value of current, which was of the order of microamps.

\section{Results and discussion}

\subsection{Potential range of anodic passive films}

The potential range where carbon steel, chromium steel and HSS are able to form a passive oxide film in 0.5 $\mathrm{M} \mathrm{NaHCO}_{3}$ and $0.5 \mathrm{M} \mathrm{NaHCO}_{3}+0.01 \mathrm{M} \mathrm{KCl}$ is shown in Fig. 1. These regions were $0.0-0.9 \mathrm{~V}$ for carbon steel, -0.2 to $0.4 \mathrm{~V}$ for chromium steel and -0.1 to $0.3 \mathrm{~V}$ versus SCE for HSS. A detailed study of these polarisation curves has been carried out [5]. In particular, the passive currents gave some insight into the nature of the passive films.

The appearance of one peak in the polarisation curves of Fig. 1 for chromium steel and two or three peaks for HSS is probably related to electrochemical reactions in the solid state involving the transition to higher oxidation states of $\mathrm{Cr}$ in both chromium steel and HSS and also of Mo and W in the case of HSS. This deduction is supported by work on type 304 stainless steel, which contains $\mathrm{Cr}$, in borate buffer solution ( $\mathrm{pH}$ 8.45): a current peak around $0.5 \mathrm{~V}$ versus SCE was observed and was attributed to the oxidation of $\mathrm{Cr}$ (III) to $\mathrm{Cr}$ (IV) within the film and the formation of soluble $\mathrm{CrO}_{4}^{2-}$ according to:

$\mathrm{Cr}_{\mathrm{Cr}}+4 \mathrm{H}_{2} \mathrm{O} \rightarrow \mathrm{CrO}_{4}^{2-}+\mathrm{V}_{\mathrm{Cr}}^{3^{\prime}}+8 \mathrm{H}^{+}+3 \mathrm{e}^{-}$

in which $\mathrm{Cr}_{\mathrm{Cr}}$ represents a $\mathrm{Cr}(\mathrm{III})$ cation in the passive film and $\mathrm{V}_{\mathrm{Cr}}^{3}$ a cation vacancy that is generated $[3,10]$.

The potential corresponding to these current peaks and the transitions they represent can be expected to have an influence on the impedance spectra.

\subsection{Impedance measurements}

The impedance spectra of carbon steel, chromium steel and HSS were obtained, in $100 \mathrm{mV}$ steps, in

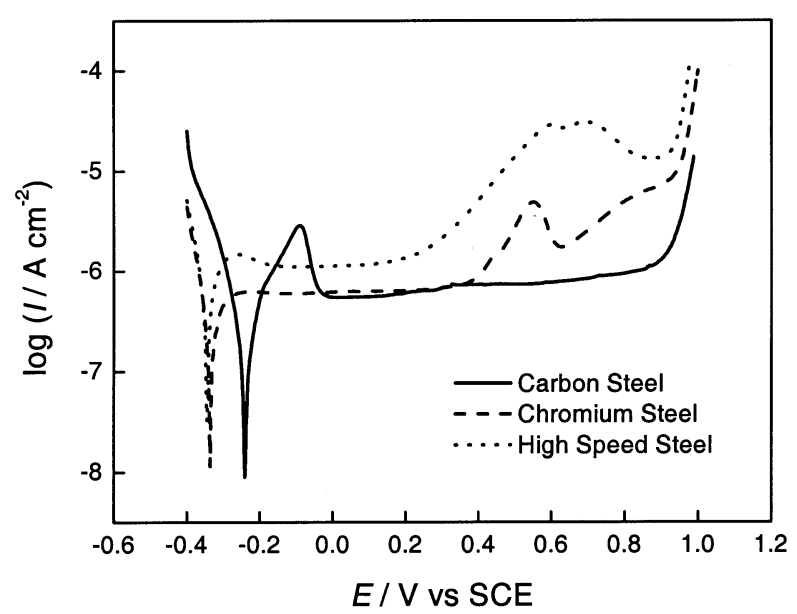

Fig. 1. Polarisation curves for the steels after passivation in $0.5 \mathrm{M}$ $\mathrm{NaHCO}_{3}$ solution. Scan in positive direction at $2 \mathrm{mV} \mathrm{s}^{-1}$. 

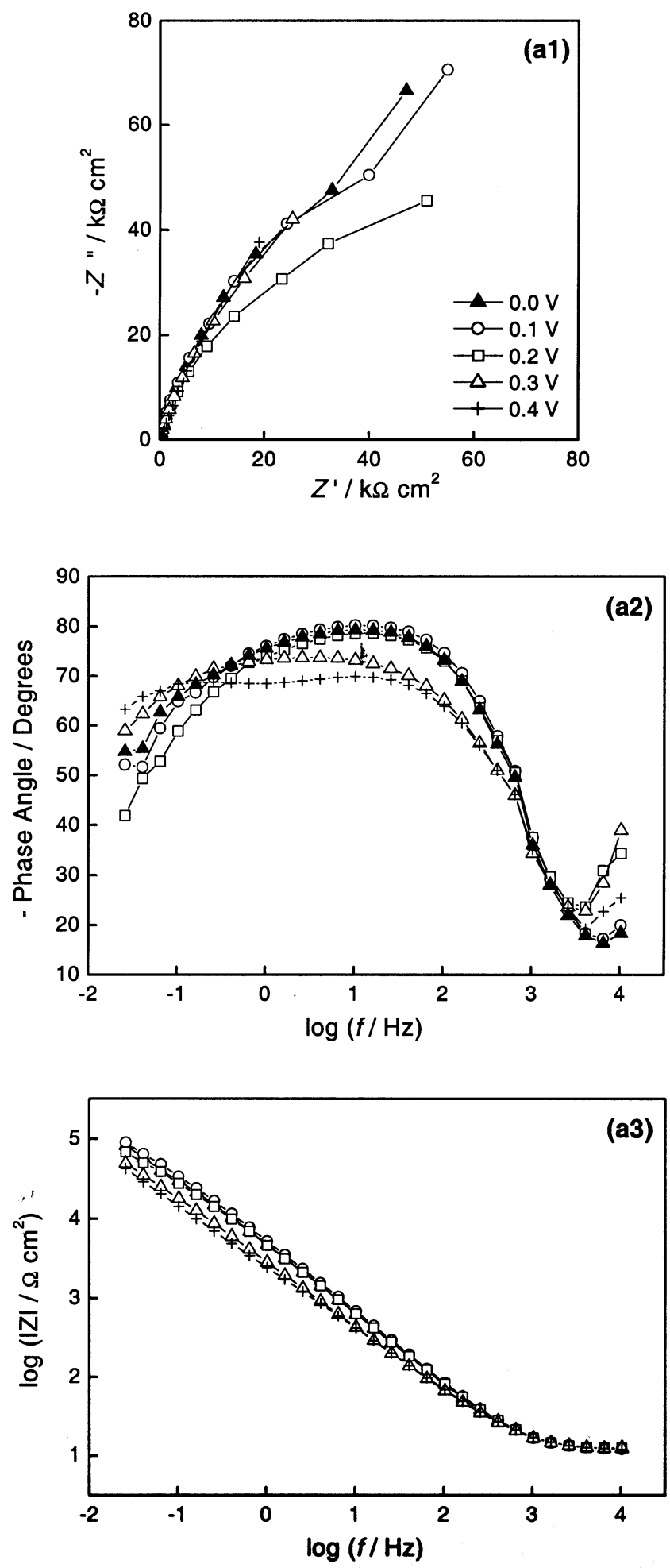
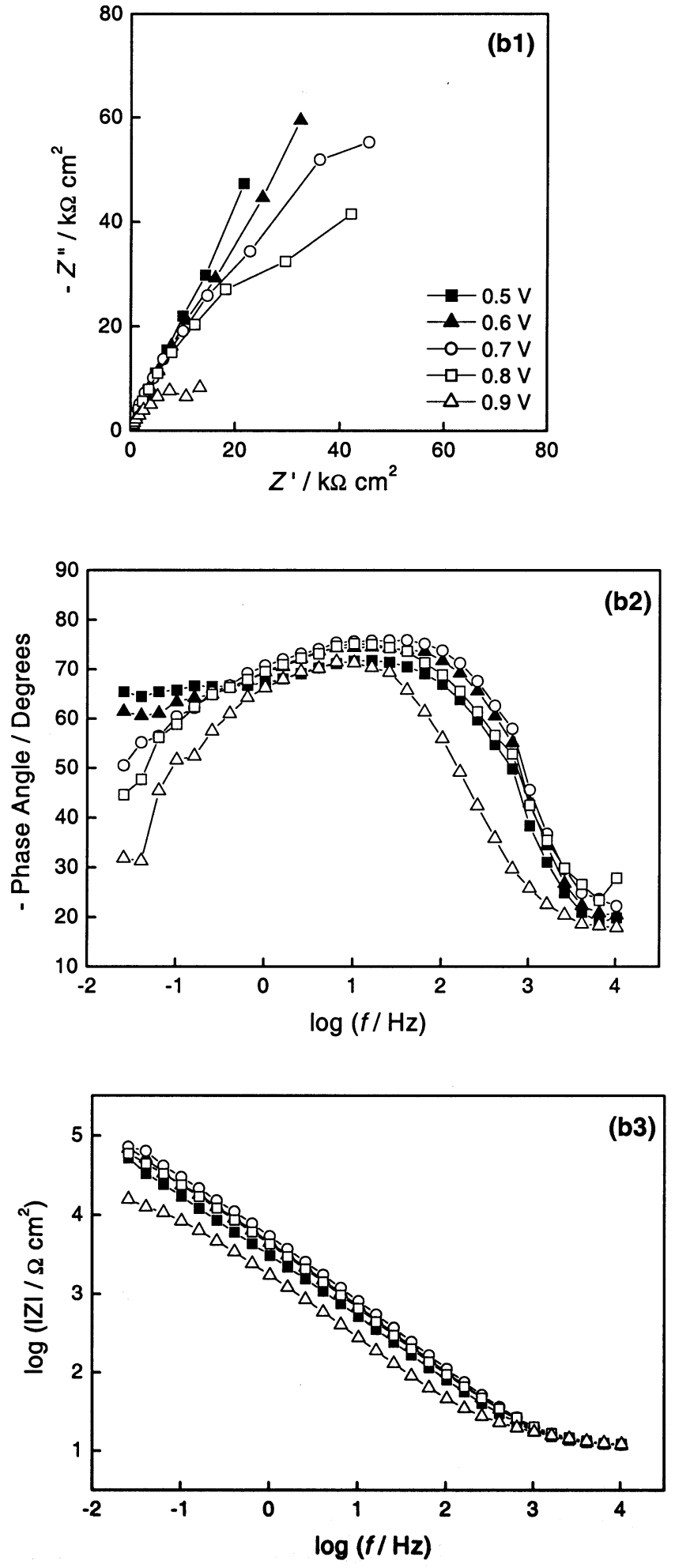

Fig. 2. Impedance spectra at potentials within the anodic passive region of carbon steel in $0.5 \mathrm{M} \mathrm{NaHCO}_{3}$ solution: plots in complex plane ( $\mathrm{a}_{1}$, $\mathrm{b}_{1}$ ), and corresponding Bode phase angle $\left(a_{2}, b_{2}\right)$ and Bode impedance magnitude $\left(a_{3}, b_{3}\right)$ plots.

bicarbonate solutions over the entire passive anodic region of each steel sample, as well as in the transpassive anodic regions of chromium steel and HSS. These are illustrated in Figs. 2-4.
Fitting of the spectra was done by an equivalent electrical circuit. Several models of circuits to fit our experimental data were attempted. The best results (best agreement between experiment and fitting for all three 

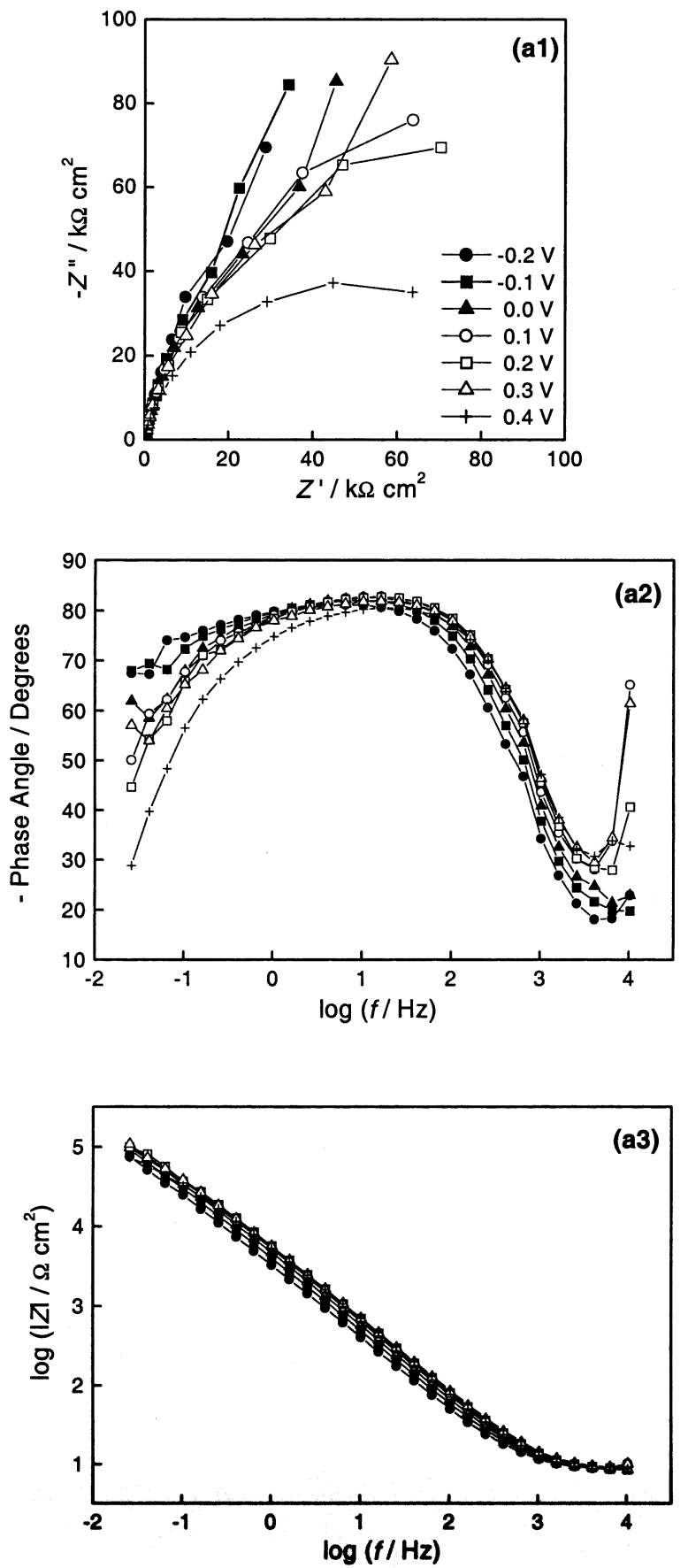
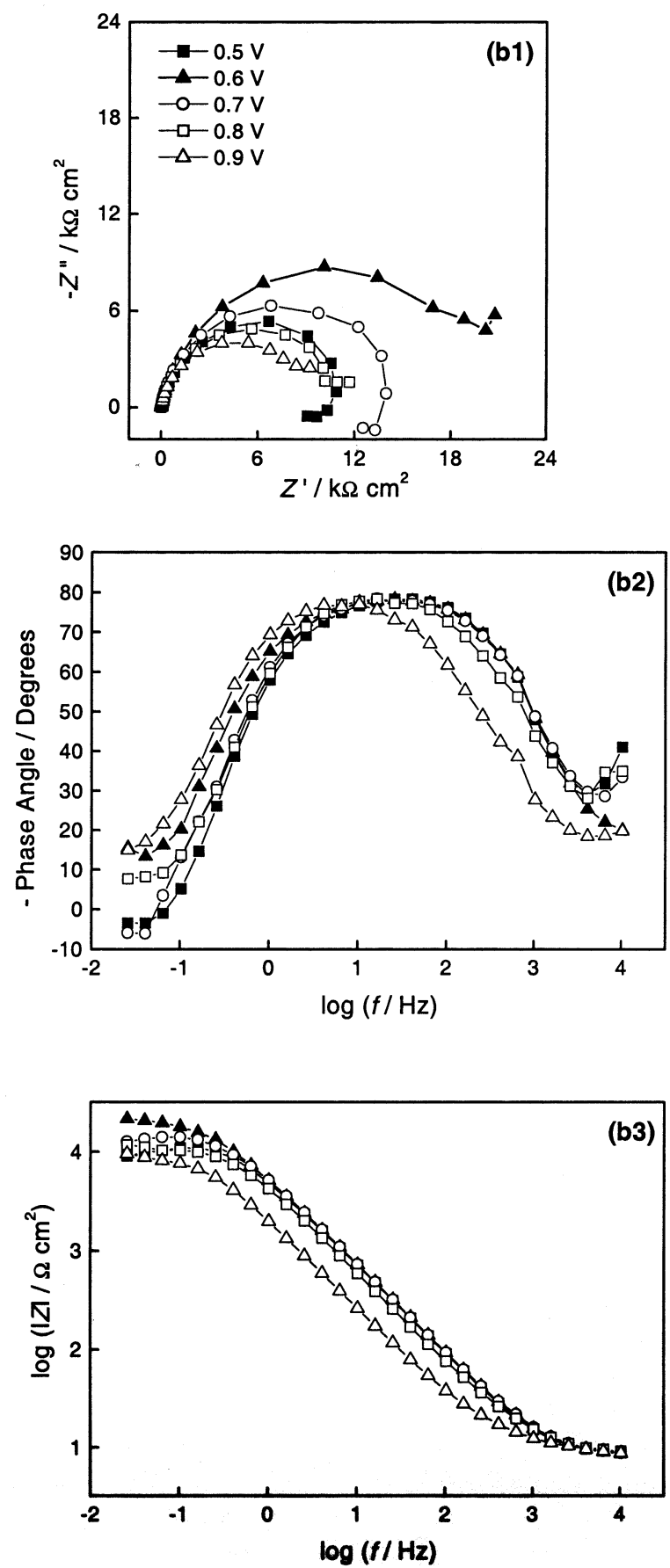

Fig. 3. Impedance spectra at potentials within the anodic passive $(E \leq 0.4 \mathrm{~V})$ and transpassive $(E>0.5 \mathrm{~V})$ regions of chromium steel $\left(450{ }^{\circ} \mathrm{C}\right)$ in 0.5 $\mathrm{M} \mathrm{NaHCO}_{3}$ solution: plots in complex plane $\left(\mathrm{a}_{1}, \mathrm{~b}_{1}\right)$, and corresponding Bode phase angle $\left(\mathrm{a}_{2}, \mathrm{~b}_{2}\right)$ and Bode impedance magnitude $\left(\mathrm{a}_{3}\right.$, $\left.\mathrm{b}_{3}\right)$ plots.

steels and at all values of potential) were obtained with the equivalent circuit presented in Fig. 5(a), a frequency range from 0.04 to $4000 \mathrm{~Hz}$ being used for fitting. This same equivalent circuit or a simplified combination has been used for passivated iron [1], stainless steel [2], aluminium [11] and tin [12]. Another suggested circuit for semiconductor thin films comprises $R$ and $C$ in parallel combination, representing the semiconductor passive oxide film, with a third parallel branch, com- posed of $R C$ in series, representing the contribution of surface states [13]; it was not possible to fit the data using this circuit.

The equivalent circuit, Fig. 5(a), comprises the cell resistance, $R_{\Omega^{\prime \prime}} C P E_{1}$ representing the capacity of the passive oxide film, including the semiconductor space charge layer, $C_{\mathrm{SC}}$ (see later), in parallel with the resistance, $R_{1}$, representing the charge transfer at the two interfaces, metal $\mid$ film and film $\mid$ solution. This 

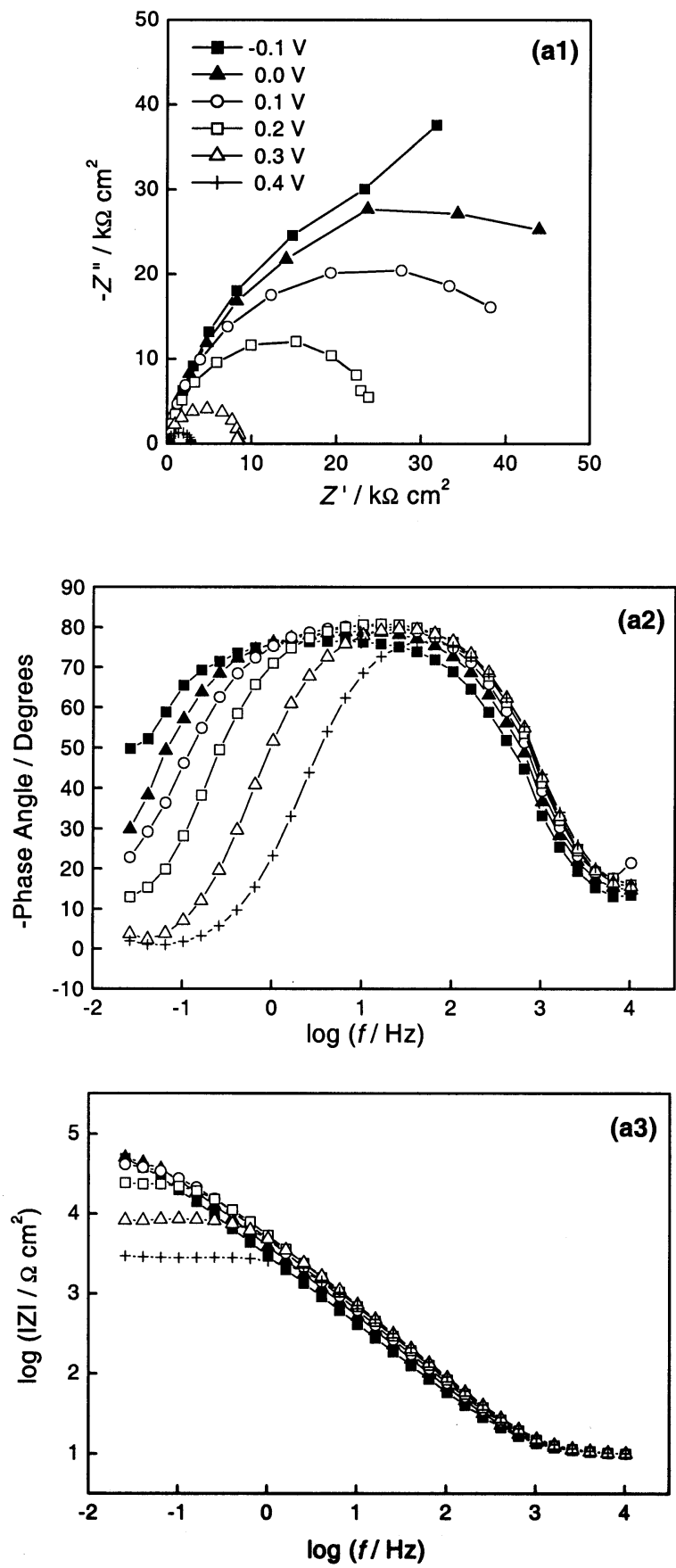
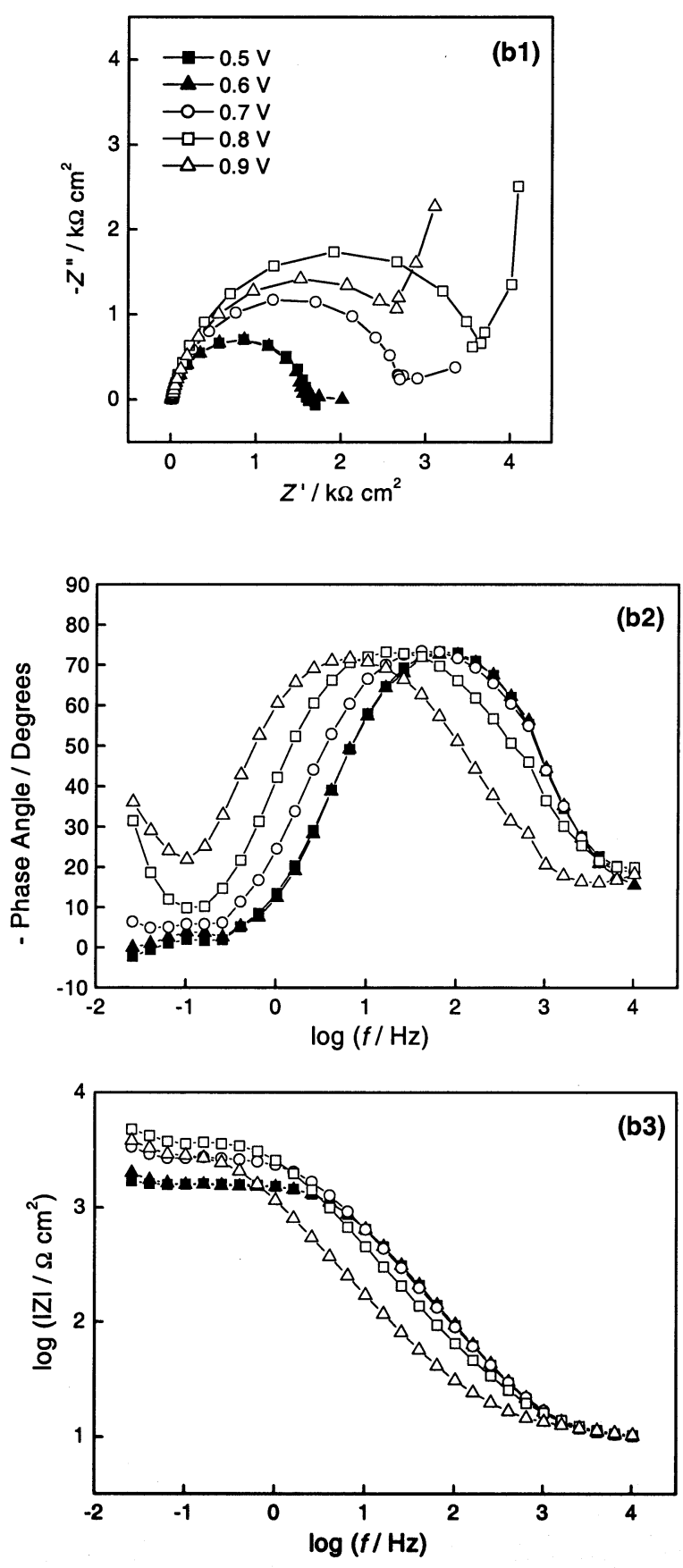

Fig. 4. Impedance spectra at potentials within the anodic passive $(E \leq 0.3 \mathrm{~V})$ and transpassive $(E>0.4 \mathrm{~V})$ regions of as-received HSS in $0.5 \mathrm{M}$ $\mathrm{NaHCO}_{3}$ solution: plots in complex plane $\left(a_{1}, b_{1}\right)$, and corresponding Bode phase angle $\left(a_{2}, b_{2}\right)$ and Bode impedance magnitude $\left(a_{3}, b_{3}\right)$ plots.

combination is in series with a $C P E_{2} / R_{2}$ parallel combination representing the contribution of the movement of vacancies and charged species through the oxide film at lower frequency. The full circuit was used to fit the data for carbon steel over the entire passive zone and for chromium steel up to $+0.4 \mathrm{~V}$. For chromium steel above $+0.4 \mathrm{~V}$ applied potential and HSS over the entire potential range, the $R_{2} C P E_{2}$ element was omitted. An example is shown in Fig. 5(b).
Carbon steel over the whole range and as-received chromium steel had similar impedance behaviour at potentials up to $0.3 \mathrm{~V}$. Tables 1 and 2(a) show numerical values for the various circuit parameters, with a value of $n$ close to unity. Values of $R_{1}$ are of the order of $100 \mathrm{k} \Omega$ $\mathrm{cm}^{2}$ and represent the passive film resistance, which reaches its highest value in the middle of the range, as would be expected. Values of $C P E_{1}$ also reach a maximum at these potentials. Large values of $C P E_{2}$ 
(a)

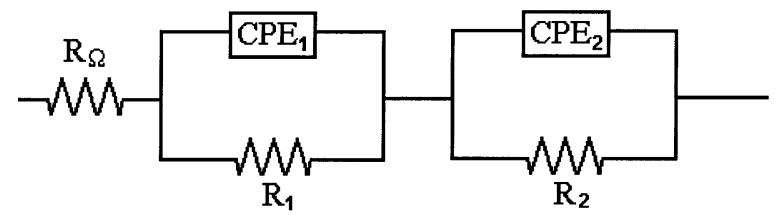

(b)
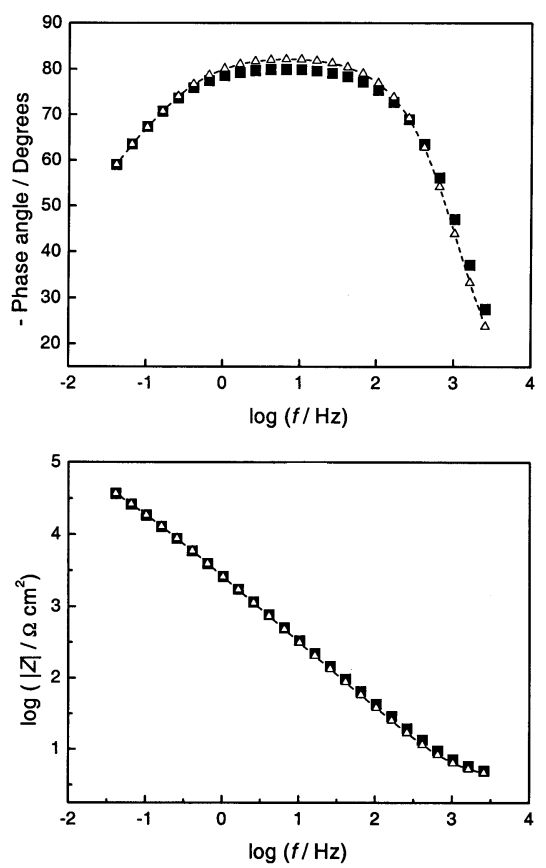

Fig. 5. (a) Equivalent circuit used to adjust the experimental impedance data of carbon steel (entire potential range) and chromium steels $(E \leq 0.4 \mathrm{~V})$. For chromium steels $(E \geq 0.5 \mathrm{~V})$ and HSS (entire potential range) the $R_{2} C P E_{2}$ parallel combination was omitted. (b) Example of spectrum fitting for chromium steel heat-treated at $450{ }^{\circ} \mathrm{C}$ at $E=0.0 \mathrm{~V}$ vs. SCE, $\mathbf{\square}$, experimental points; $\Delta$, and dotted line are result of fitting to the circuit in (a).

were needed to adjust the circuit but the values of $R_{2}$ are low, around $10 \mathrm{k} \Omega \mathrm{cm}^{2}$.
HSS as-received, Table 3(a), has a different impedance behaviour from that of carbon steel over the whole passive region. Above $0.3 \mathrm{~V}$, spectra from asreceived chromium steel alter their shape and become similar to those of HSS for the same applied potentials. Film resistances are lower and capacitances also. The observed semicircles can be adjusted by the $R_{1} C P E_{1}$ parallel combination. At more positive potentials $>0.4$ $\mathrm{V}$ versus SCE, the impedance decreases drastically for chromium steel, see Fig. 3(b1-b3), more gradually for HSS, see Fig. 4(b1-b3), and a time constant at the lowest frequencies appears. This change in the impedance behaviour coincides with the potentials at which peaks in the polarisation curves are observed, Fig. 1, ascribed to chromium transpassivation. Plots of film resistance versus potential are shown in Fig. 6 and show clearly the progressive decrease for HSS and the abrupt drop for chromium steel.

At potentials near the peak potential it would be necessary to use a negative capacitance, for example, to model the low frequency behaviour. Whilst the actual significance of this inductance is not clear, it is consistent with the oxidation current being impeded by an inductive current flowing in the opposite direction at the electrode / electrolyte interface [14]. This may be associated with the existence of the passive film on the steel surface. At more positive potentials, the time constant at low frequencies can be expressed by a positive value, explained by the passive film now imposing mass transfer limitations, instead of inductive effects.

Qualitatively, heat-treated chromium steel $\left(450{ }^{\circ} \mathrm{C}\right)$ and HSS $\left(550^{\circ} \mathrm{C}\right)$ show similar impedance behaviour to those of the respective as-received steels. However, the $R_{1}$ values are higher, compare in Tables 2 and 3 and in Fig. 6, particularly for chromium steel (Fig. 6(a)), suggesting that heat treatment alters the properties of the passive film formed. In fact, heat treatment leads to a higher fraction of alloying elements in solid solution in the iron matrix instead of forming carbides [15]. As a consequence, the structure and thence the electrical properties of the passive film, which grows at the

Table 1

Equivalent circuit fitting for carbon steel passivated in $0.5 \mathrm{M} \mathrm{NaHCO}_{3}$ solution, pH 8.6

\begin{tabular}{lcccccc}
\hline$E(\mathrm{~V}$ vs. SCE $)$ & $C P E_{1}\left(\Omega^{-1} \mathrm{~s}^{n} \mathrm{~cm}^{-2} \times 10^{6}\right)$ & $n_{1}$ & $R_{1}\left(\mathrm{k} \Omega \mathrm{cm}^{2}\right)$ & $C P E_{2}\left(\Omega^{-1} \mathrm{~s}^{n} \mathrm{~cm}^{-2} \times 10^{6}\right)$ & $n_{2}$ & $R_{2}\left(\mathrm{k} \Omega \mathrm{cm}^{2}\right)$ \\
\hline 0.0 & 65.2 & 0.96 & 126 & 91 & 0.87 & 10.9 \\
0.1 & 44.7 & 0.90 & 136 & 162 & 0.92 \\
0.2 & 68.1 & 0.87 & 107 & 104 & 0.92 & 11.9 \\
0.3 & 111 & 0.87 & 181 & 227 & 0.75 & 14.6 \\
0.4 & 98.1 & 0.80 & 292 & 515 & 0.95 & 0.2 \\
0.5 & 85.4 & 0.80 & 280 & 319 & 0.89 \\
0.6 & 59.3 & 0.83 & 226 & 128 & 1.0 \\
0.7 & 47.2 & 0.85 & 172 & 97 & 0.90 \\
0.8 & 58.3 & 0.85 & 92 & 171 & 0.90 & 3.4 \\
\hline
\end{tabular}


Table 2

Equivalent circuit fitting for chromium steel, passivated in $0.5 \mathrm{M} \mathrm{NaHCO}_{3}$ solution, pH 8.6

\begin{tabular}{|c|c|c|c|c|c|c|}
\hline$E(\mathrm{~V}$ vs. SCE) & $C P E_{1}\left(\Omega^{-1} \mathrm{~s}^{n} \mathrm{~cm}^{-2} \times 10^{6}\right)$ & $n_{1}$ & $R_{1}\left(\mathrm{k} \Omega \mathrm{cm}^{2}\right)$ & $C P E_{2}\left(\Omega^{-1} \mathrm{~s}^{n} \mathrm{~cm}^{-2} \times 10^{6}\right)$ & $n_{2}$ & $R_{2}\left(\mathrm{k} \Omega \mathrm{cm}^{2}\right)$ \\
\hline \multicolumn{7}{|l|}{ (a) As-received } \\
\hline-0.2 & 183 & 0.85 & 82.6 & 487 & 0.79 & 3.1 \\
\hline-0.1 & 217 & 0.90 & 85.3 & 208 & 0.80 & 9.8 \\
\hline 0.0 & 195 & 0.90 & 88.3 & 172 & 0.80 & 9.9 \\
\hline 0.1 & 195 & 0.90 & 80.6 & 150 & 0.80 & 10.6 \\
\hline 0.2 & 186 & 0.90 & 68.5 & 147 & 0.80 & 9.5 \\
\hline 0.3 & 198 & 0.90 & 65.3 & 143 & 0.80 & 9.0 \\
\hline 0.4 & 171 & 0.85 & 34.8 & 170 & 0.80 & 5.1 \\
\hline 0.5 & 78 & 0.84 & 7.1 & - & - & - \\
\hline 0.6 & 103 & 0.80 & 20.0 & - & - & - \\
\hline 0.7 & 97 & 0.80 & 16.7 & - & - & - \\
\hline 0.8 & 112 & 0.80 & 10.8 & - & - & - \\
\hline 0.9 & 209 & 0.80 & 6.8 & - & - & - \\
\hline \multicolumn{7}{|c|}{ (b) After heat treatment at $450{ }^{\circ} \mathrm{C}$} \\
\hline-0.2 & 70.4 & 0.92 & 500 & 246 & 0.90 & 5.9 \\
\hline-0.1 & 60.1 & 0.90 & 277 & 209 & 0.95 & 11.1 \\
\hline 0.0 & 49.2 & 0.94 & 168 & 147 & 0.90 & 8.1 \\
\hline 0.1 & 50.1 & 0.93 & 207 & 104 & 0.92 & 13.4 \\
\hline 0.2 & 38.8 & 0.93 & 162 & 122 & 0.92 & 4.4 \\
\hline 0.3 & 45.9 & 0.92 & 161 & 110 & 0.92 & 10.6 \\
\hline 0.4 & 44.0 & 0.92 & 81.7 & 114 & 0.90 & 4.4 \\
\hline 0.5 & 27.2 & 0.98 & 11.1 & - & - & - \\
\hline 0.6 & 33.2 & 0.88 & 21.5 & - & - & - \\
\hline 0.7 & 28.3 & 0.95 & 14.2 & - & - & - \\
\hline 0.8 & 36.5 & 0.93 & 10.9 & - & - & - \\
\hline 0.9 & 90.2 & 0.90 & 9.4 & - & - & - \\
\hline
\end{tabular}

Table 3

Equivalent circuit fitting for $\mathrm{HSS}$ passivated in $0.5 \mathrm{M} \mathrm{NaHCO}$ solution, $\mathrm{pH} 8.6$

\begin{tabular}{|c|c|c|c|}
\hline$E(\mathrm{~V}$ vs. $\mathrm{SCE})$ & $C P E_{1}\left(\Omega^{-1} \mathrm{~s}^{n} \mathrm{~cm}^{-2} \times 10^{6}\right)$ & $n_{1}$ & $R_{1}\left(\mathrm{k} \Omega \mathrm{cm}^{2}\right)$ \\
\hline \multicolumn{4}{|l|}{ (a) As-received } \\
\hline-0.1 & 67.4 & 0.86 & 87.4 \\
\hline 0.0 & 47.8 & 0.89 & 65.5 \\
\hline 0.1 & 39.8 & 0.86 & 49.8 \\
\hline 0.2 & 32.6 & 0.92 & 26.1 \\
\hline 0.3 & 26.6 & 0.96 & 8.8 \\
\hline 0.4 & 26.8 & 0.94 & 2.9 \\
\hline 0.5 & 28.4 & 0.92 & 1.6 \\
\hline 0.6 & 26.9 & 0.93 & 1.6 \\
\hline 0.7 & 33.2 & 0.91 & 2.8 \\
\hline 0.8 & 50.9 & 0.88 & 4.0 \\
\hline 0.9 & 151 & 0.87 & 3.4 \\
\hline \multicolumn{4}{|c|}{ (b) After heat treatment at $550{ }^{\circ} \mathrm{C}$} \\
\hline-0.1 & 46.2 & 0.88 & 105 \\
\hline 0.0 & 35.5 & 0.91 & 77.2 \\
\hline 0.1 & 32.1 & 0.91 & 55.9 \\
\hline 0.2 & 27.9 & 0.92 & 52.0 \\
\hline 0.3 & 25.3 & 0.94 & 31.9 \\
\hline 0.4 & 24.3 & 0.94 & 19.8 \\
\hline 0.5 & 24.0 & 0.93 & 13.5 \\
\hline 0.6 & 24.1 & 0.93 & 9.0 \\
\hline 0.7 & 23.5 & 0.95 & 11.0 \\
\hline 0.8 & 30.2 & 0.92 & 11.4 \\
\hline 0.9 & 71.9 & 0.92 & 8.7 \\
\hline
\end{tabular}

surface, are also altered. This effect of heat treatment was not evidenced through passive current values (from polarisation plots and potentiostatic measurements) or from open circuit potential measurements [5]. These results suggest that impedance measurements are more sensitive to the properties of the different passive films formed.

Addition of $10 \mathrm{mM} \mathrm{KCl}$ to the passivating $0.5 \mathrm{M}$ $\mathrm{NaHCO}_{3}$ solution does not cause any significant difference in the impedance spectra. For carbon steel these measurements were not made in the presence of 10 $\mathrm{mM}$ chloride, because the passivity region becomes very narrow; the anion effect can be clearly seen in the polarisation curves $[5,16]$.

\subsection{Semiconductor properties of the passive films (Mott-Schottky plots)}

In order to gain insight into the semiconductor properties of the passive films formed both in $0.5 \mathrm{M}$ $\mathrm{NaHCO}_{3}$ and in $0.5 \mathrm{M} \mathrm{NaHCO}+40.01 \mathrm{M} \mathrm{KCl}$, the capacitance values, $C$, were calculated from the imaginary part of the impedance at $f=1.63 \mathrm{kHz}$, a commonlyused frequency for this type of analysis $[14,17,18]$. At such high frequencies, these capacitance values, which can be linked to $C P E_{1}$ mentioned above, are assumed to reflect mainly the capacitance of the semiconductor 

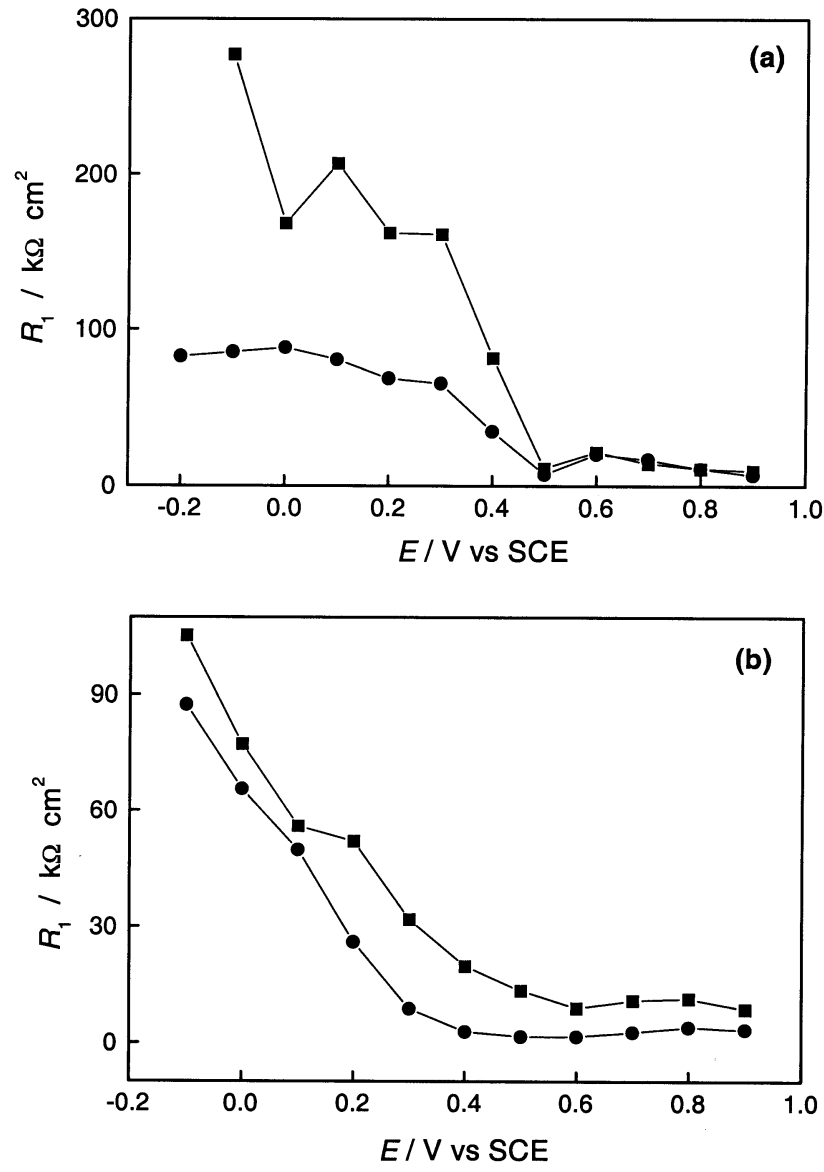

Fig. 6. Film resistance, $R_{1}$, as a function of potential in $0.5 \mathrm{M}$ $\mathrm{NaHCO}_{3}$. (a) Chromium steel as-received and heat-treated at $450{ }^{\circ} \mathrm{C}$; (b) HSS as-received and heat-treated at $550{ }^{\circ} \mathrm{C}$. - , as-received; after heat-treatment.

space-charge layer, $C_{\mathrm{SC}}$, since the contribution of the double layer capacitance is assumed to be negligible [19].

The Mott-Schottky relationship $\left(1 / C_{\mathrm{SC}}^{2}\right.$ vs. $\left.E\right)$ for an n-type semiconductor is expressed by Eq. (4) [20,21]:

$\frac{1}{C_{\mathrm{SC}}^{2}}=\frac{2}{\varepsilon \varepsilon_{0} e N_{\mathrm{D}}}\left(E-E_{\mathrm{fb}}-\frac{k T}{e}\right)$

where $\varepsilon$ is the dielectric constant of the passive film ( $\varepsilon$ was assumed to be 10 , which is the dielectric constant for $\left.\gamma-\mathrm{Fe}_{2} \mathrm{O}_{3}\right), \varepsilon_{0}$ is the permittivity of free space $(8.854 \times$ $\left.10^{-14} \mathrm{~F} \mathrm{~cm}^{-1}\right), e$ is the electron charge $(1.602189 \times$ $\left.10^{-19} \mathrm{C}\right), N_{\mathrm{D}}$ is the donor density, $E_{\mathrm{fb}}$ is the flat band potential, $k$ is the Boltzmann constant $\left(1.38066 \times 10^{-23}\right.$ $\left.\mathrm{J} \mathrm{K}^{-1}\right)$ and $T$ is the absolute temperature $(298 \mathrm{~K}) . N_{\mathrm{D}}$ is determined from the slope of the experimental $1 / C_{\mathrm{SC}}^{2}$ versus $E$ plots, and $E_{\mathrm{fb}}$ by extrapolation to $1 / C_{\mathrm{SC}}^{2}=0$.

The Mott-Schottky plots of the various steels, Fig. 7, present predominantly donor-type semiconductivity, as the slopes are always positive.

The plot for carbon steel presents a rather narrow linear region (0.4-0.7 V vs. SCE). The region of nonlinearity can be attributed to a change in donor type and/or donor density with potential [22]. Sikora et al. [23] and Goossens et al. [24] attributed the non-linearity to the fact that the thickness of a passive film increases linearly with the applied potential (as does the donor density). According to Cheng and Luo [25], two possible dopants in this case are interstitial iron and oxygen vacancies. However, it is impossible for interstitial iron to be the dopant because the iron atoms are so large that there are few of them in interstitial positions due to the energy barrier. Thus, the dopants in the passive film on carbon steel should be mainly oxygen vacancies. This excludes a change in donor type as being the reason for the non-linearity observed for carbon steel.

Chromium steel and HSS, as-received and heattreated, in the presence or absence of chloride, also show n-type semiconductivity, and there is a linear region in the Mott-Schottky plot over almost the whole potential range, see Fig. 7. This implies that the film thickness does not change with the applied potential, and that values of $N_{\mathrm{D}}$ are constant. From these plots, $N_{\mathrm{D}}$ and $E_{\mathrm{fb}}$ were calculated using Eq. (4), as was the thickness of the space-charge layer, $\delta_{\mathrm{SC}}$, by the following equation for an n-type semiconductor:

$\delta_{\mathrm{SC}}=\left[\frac{2 \varepsilon \varepsilon_{0}}{e N_{\mathrm{D}}}\left(E-E_{\mathrm{fb}}-\frac{k T}{e}\right)\right]^{1 / 2}$

These values are shown in Fig. 8.

It is clear from Fig. 8(a) that the donor density is lower for passive films grown on HSS than on chromium steel, while the space-charge layer, Fig. 8(b), is thicker. In the absence of chloride ion, heat treatment leads to lower donor densities and an increase in passive film thickness and a better linearity in the MottSchottky plots. This is in agreement with an increase of charge transfer resistance of the heat-treated steels, as discussed before (see Fig. 6), and with their higher pitting corrosion resistance.

No significant differences can be seen in the $E_{\mathrm{fb}}$ values in Fig. 8(c) between the two steels although heat treatment leads to more positive values. These values thus show clear indications of the influence of heat treatment on passive film characteristics.

Correlations can be made between these plots. It is known that the thicker the space-charge layer, the thicker the passive film and consequently less susceptible is the film to breakdown. At the same time, the smaller $N_{\mathrm{D}}$, the lower are the chances of film breakdown and pitting initiation, since defects are potential sites where these processes are supposed to occur. So, it can be concluded that the passive film formed on HSS has a more stable structure, and thence a higher protection against corrosion, compared with that of the passive film formed on chromium steel. This reflects the effect of alloying on the passivating properties of the steels in bicarbonate solution. 

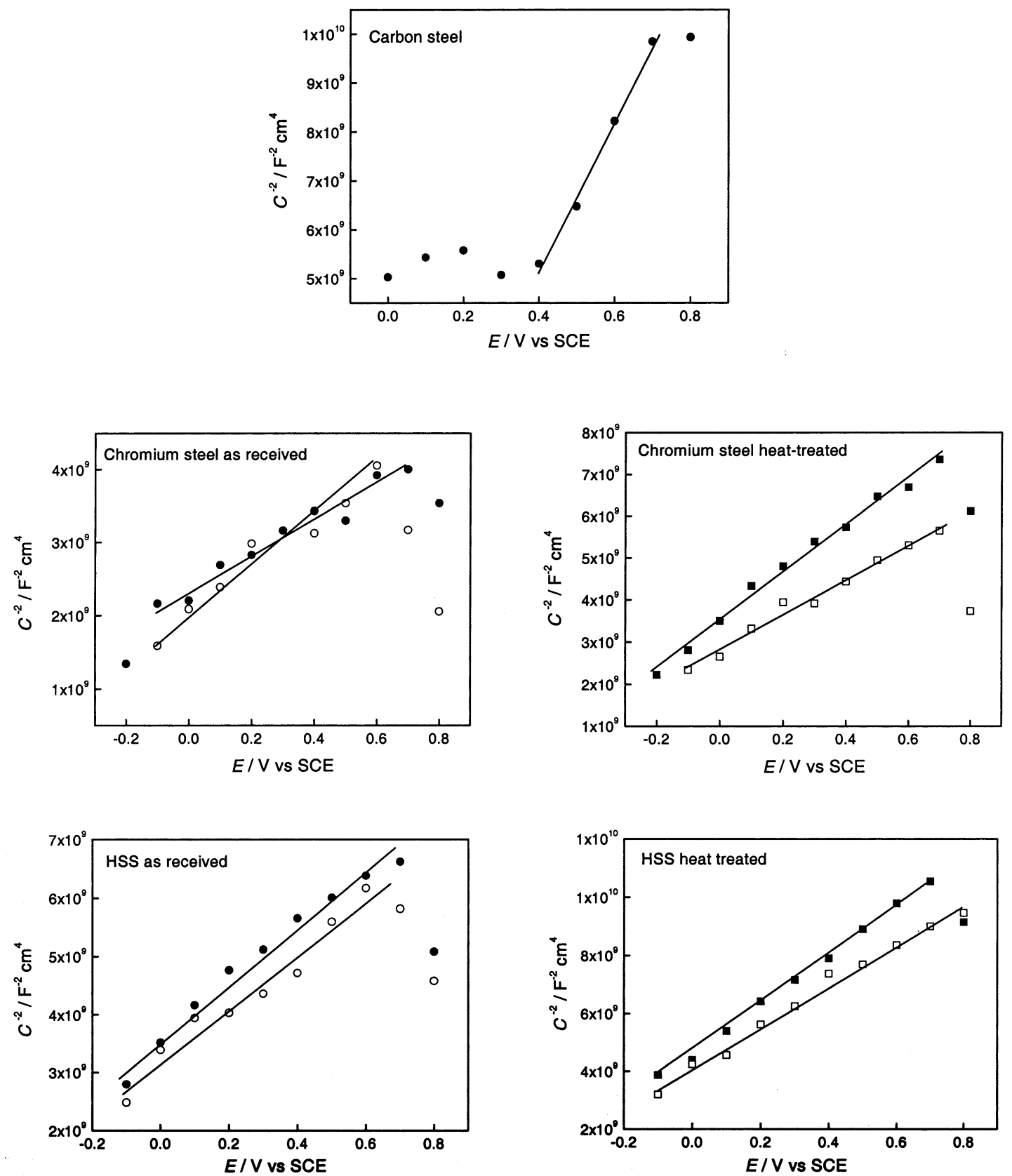

Fig. 7. Mott-Schottky plots for the steels. Solid symbols, $0.5 \mathrm{M} \mathrm{NaHCO}_{3}$; open symbols, $0.5 \mathrm{M} \mathrm{NaHCO}_{3}+0.01 \mathrm{M} \mathrm{KCl}$.

The passive film formed on carbon steel in bicarbonate will have the worst protective properties, compared with those formed on chromium steel and HSS, since it is heavily doped and disordered $\left(N_{\mathrm{D}}\right.$ of the order of $10^{22}$ ), the space-charge layer being very thin $(1-6 \AA)$ [25], and consequently the passive film thickness.

The effect of chloride ion on the semiconductor properties of the passive films is not very significant. There is, however, evidence of space charge layer thinning in the presence of $10 \mathrm{mM}$ chloride (see Fig. 8(b)), which implies a thinning of the passive film, as would be predicted. It also appears to partially annul any differences in the flat band potential caused by heat treatment. Thus, any effect of chloride ion is most seen through the impedance response of these passive films grown on the steels.

\section{Conclusions}

This study has shown that differences between the characteristics of passive films formed on the three types of mild steel studied in bicarbonate solution can be 

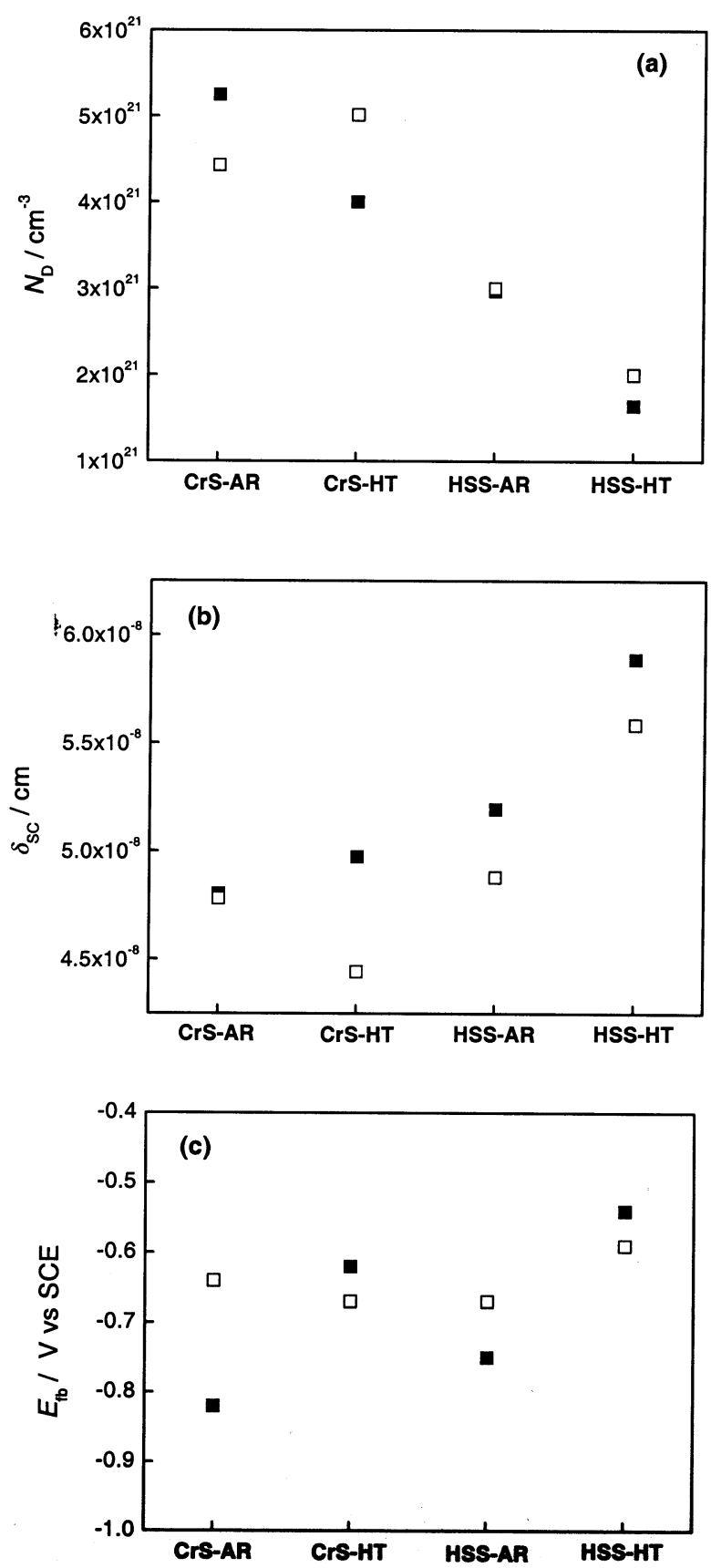

Fig. 8. (a) Donor density, $N_{\mathrm{D}}$; (b) thickness of the space-charge layer, $\delta_{\mathrm{SC}}$ and (c) flat-band potential, $E_{\mathrm{fb}}$, of the passive films formed on: $\mathrm{CrS}$-AR-chromium steel as-received; $\mathrm{CrS}-\mathrm{HT}$-chromium steel $\left(450{ }^{\circ} \mathrm{C}\right)$; HSS $-\mathrm{AR}-\mathrm{HSS}$ as-received; HSS-HT-HSS $\left(550{ }^{\circ} \mathrm{C}\right)$ in (匹), $0.5 \mathrm{M} \mathrm{NaHCO}_{3}$ and (口), $0.5 \mathrm{M} \mathrm{NaHCO}_{3}+0.01 \mathrm{M} \mathrm{KCl}$.

easily distinguished by electrochemical impedance. In particular, it was shown that:

- carbon steel and chromium steel had similar impedance behaviour at potentials up to $0.3 \mathrm{~V}$ (passive zone of both). Carbon steel remains in the passive state until $0.9 \mathrm{~V}$.

- Above $0.3 \mathrm{~V}$ spectra from chromium steel alter their shape and magnitude and become similar to those of
HSS for the same applied potentials, ascribed to the transpassive dissolution of $\mathrm{Cr}$.

- HSS has a different impedance behaviour from that of carbon steel and chromium steel in the passive anodic region.

- Heat treatment leads to a change in the properties of the passive films.

All passive films exhibit n-type semiconductor behaviour; the dopants in the passive films are mainly oxygen vacancies. The calculated donor densities are higher and the space charge region thinner for chromium steel, compared with HSS, suggesting that the passive film formed is less protective. Non-linearity in the MottSchottky plots for carbon steel and instability in the presence of chloride ion suggested that it is the least protected of the three types of steel.

It was seen that differences in passive films formed are due not only to the composition of the substrate but also to heat treatment and to a small extent to the presence of chloride ion in the passivating solution, except for carbon steel. Heat treatment led to higher film resistances, reflected in lower donor densities, ascribed to the higher fraction of alloying elements in solid solution in the iron matrix. Although addition of $10 \mathrm{mM} \mathrm{KCl}$ to the passivating $0.5 \mathrm{M} \mathrm{NaHCO}_{3}$ solution does not cause any significant difference in the impedance spectra, there is evidence of thinning of the space charge layer.

\section{Acknowledgements}

Valéria A. Alves thanks CNPq (Brazil), project 200396/99-4, for a post-doctoral fellowship. Financial support from Fundação para a Ciência e Tecnologia (FCT)-ICEMS (Research Unit 103) is gratefully acknowledged.

\section{References}

[1] E.M.A. Martini, I.L. Muller, Corros. Sci. 42 (2000) 443.

[2] D. Wallinder, J. Pan, C. Leygraf, A. Delblanc-Bauer, Corros. Sci. 41 (1999) 275.

[3] Q. Yang, J.L. Luo, Electrochim. Acta 45 (2000) 3927.

[4] P. Schmuki, H. Böhni, Werkst. Korros. 42 (1991) 203.

[5] V.A. Alves, C.M.A. Brett, Corros. Sci., submitted.

[6] V.A. Alves, C.M.A. Brett Mater. Sci. Forum, submitted.

[7] D.H. Davies, G.T. Burstein, Corrosion 36 (1980) 416.

[8] Y.F. Cheng, M. Wilmott, J.L. Luo, Appl. Surf. Sci. 152 (1999) 161.

[9] B.R. MacDougall, M.J. Graham, in: P. Marcus, J. Oudar (Eds.), Corrosion Mechanisms in Theory and Practice, Marcel Dekker, New York, 1995.

[10] N. Ramasubramian, N.P. Preocanin, R.D. Davison, J. Electrochem. Soc. 132 (1985) 793.

[11] S. Gudic, J. Radosevic, M. Kliskic, J. Appl. Electrochem. 26 (1996) 1027. 
[12] M. Metikos-Hukovic, S. Omanovic, A. Jukic, Electrochim. Acta 45 (1999) 977.

[13] S.R. Morrison, Electrochemistry at Semiconductor and Oxidized Metal Electrodes, Plenum, New York, 1981, p. 124.

[14] A.L. Rudd, C.B. Breslin, J. Electrochem. Soc. 147 (2000) 1401.

[15] V.A. Alves, A. Cavaleiro, C.M.A. Brett, J. Appl. Electrochem. 31 (2001) 65.

[16] Y.F. Cheng, J.L. Luo, J. Electrochem. Soc. 146 (1999) 970.

[17] N.E. Hakiki, M. Da Cunha Belo, A.M.P. Simões, M.G.S Ferreira, J. Electrochem. Soc. 145 (1998) 3821.

[18] E. Sikora, D.D. Macdonald, J. Electrochem. Soc. 147 (2000) 4087.
[19] S.R. Morrison, Electrochemistry at Semiconductor and Oxidized Metal Electrodes, Plenum, New York, 1981, p. 26.

[20] N.F. Mott, Proc. R. Soc. London Ser. A 171 (1939) 27.

[21] W. Schottky, Z. Phys. 113 (1939) 367.

[22] M. Bojinov, G. Fabricius, T. Laitinen, K. Mäkelä, T. Saario, G. Sundholm, Electrochim. Acta 45 (2000) 2029.

[23] E. Sikora, J. Sikora, D.D. Macdonald, Electrochim. Acta 41 (1996) 783.

[24] A. Goossens, M. Vazquez, D.D. Macdonald, Electrochim. Acta 41 (1996) 35.

[25] Y.F. Cheng, J.L. Luo, Appl. Surf. Sci. 167 (2000) 113. 